\title{
Phenolation of alkali lignin of wheat straw in ionic liquid
}

\author{
Zhang Zhi-guo* \\ Collage of Chemistry and Chemical Engineering, University of the Chinese Academy of Sciences, \\ Beijing, China \\ *Corresponding author zhangzhiguo@ucas.ac.cn
}

Keywords: wheat straw, lignocellulose, phenolation, alkali lignin

Abstract. Alkali lignin is an important biorecourse. Its low reactivity and indissolubility in water make it difficult to be utilized. In present study, we verified dissolving capacity of [Bmim] $\mathrm{Cl}$ and researched the effect of some influencing factors, such as time, temperature and the amount of reactants, on the phenolation reaction in $[\mathrm{Bmim}] \mathrm{Cl}$. The results suggested that alkali lignin can be dissolved in $[\mathrm{Bmim}] \mathrm{Cl}$, and the phenolation of alkali lignin in $[\mathrm{Bmim}] \mathrm{Cl}$ is feasible

\section{Introduction}

Lignin is an important biorecourse. In nature, the amount of lignin is second only to cellulose. In recent years, more and more people focus on it. A lot of scholars and engineers have established various processes to utilize this biorecourse. For example, since there are phenolic hydroxyl groups and aldehyde groups in lignin molecule, it can be prepare to phenol formaldehyde resin, which is important plastic or adhesive. For another example, there are hydroxyls in lignin molecule, including alcohol hydroxyl and phenolic hydroxyl group. It can be used as a kind of polyols in processes of polyurethane production. However, two reason lead to poor quality of high polymer made from lignin. The first is its insolubilization. The second is that lignin is short of active group.

In order to increase its reactivity, lignin should be modified, and phenolation is an important modification method $[1,2]$. Phenolation refers to the method that the $\alpha-\mathrm{C}$ of lignin reacted with phenol at acid environment, which leads-in phenolic hydroxyl group in lignin molecular [3].

It is well known that lignin is residue or by-product of the process of cellulose extraction. Various kinds of lignin with different chemical and physical properties can be obtained from alkaline pulping, acid polishing and enzymatic hydrolysis of cellulose and hemicellulose in wood. Generally, phenolation is used in the modification of lignosulfonate [4]. Few people use the method to modify alkali lignin, because alkali lignin is insoluble in water [5].

In recent years, it was found that some ionic liquid can dissolve lignocelluloses or it components [6]. If these ionic liquid can dissolve alkali lignin too, this kind of lignin can be modified easily. In present study, we verified the dissolving capacity of a common ionic liquid, 1-butyl-3-methylimidazolium chloride $([\mathrm{Bmim}] \mathrm{Cl})[2]$ and researched the effect of some influencing factors on the phenolation reaction in $[\mathrm{Bmim}] \mathrm{Cl}$.

\section{Materials and methods}

\section{Materials}

Wheat straw was harvested from local farmers in the suburb of Xinle, Hebei Province, China.

1-butyl-3-methylimidazolium chloride $([\mathrm{Bmim}] \mathrm{Cl})$ was purchased from Henan lihua pharmaceutical co., LTD.

\section{Preparation of alkali lignin}

Ten gram wheat straw was cropped to about $10 \mathrm{~cm}$ and put in a beaker. One gram $\mathrm{NaOH}$ and 100 $\mathrm{mL}$ water was added in. The beaker was heated at $90{ }^{\circ} \mathrm{C}$ for $2 \mathrm{~h}$. Then, the filtrate was obtained by filtration. After filtration, the $\mathrm{pH}$ value of the filtrate was regulated to 2 . The precipitation was collected by centrifugalization. The obtained precipitation was dried in a vacuum oven at $60^{\circ} \mathrm{C}$ for $6 \mathrm{~h}$. 


\section{Phenolation of alkali lignin in ionic liquid}

One gram alkali lignin was mixed with $10 \mathrm{~g}[\mathrm{Bmim}] \mathrm{Cl}$ in a flask. Concentrated sulfuric acid and phenol were added in then. After the reactions, $30 \mathrm{~mL}$ deionized water was added in. the sedimentary phenolated lignin was obtained by centrifugalization. The phenolated lignin was washed for three times and dried in a in a vacuum oven at $60{ }^{\circ} \mathrm{C}$ for $6 \mathrm{~h}$.

\section{Determination of phenolic hydroxyl content of lignin}

Phenolic hydroxyl content of lignin was estimate by measuring the the absorbance of the alkaline solution relative to that of the neutral solution as the "blank" in the reference cell of the spectrophotometer $[7,8]$.

About $0.02 \mathrm{~g}$ sample and $10 \mathrm{~mL}$ borate buffer $(\mathrm{pH} 12)$ were mixed, and treated with a ultrasonicator for $20 \mathrm{~min}$ to make the sample dissolved. Then, two $200 \mu \mathrm{L}$ solution was take with a pipettor. One of them was diluted with borate buffer $(\mathrm{pH} 12)$ to $5 \mathrm{~mL}$, the other was mixed with dilute sulphuric acid $(0.05 \mathrm{~mol} / \mathrm{L})$ and diluted with phosphate buffer $(\mathrm{pH} 6)$. Then, absorbance of alkaline solution at 300 nm was measured using neutral solution as a "blank". The content of phenolic hydroxyl in sample was calculated with the eqation (1):

Moles of phenolic hydroxyl per gram $=\Delta A_{300} /(4100 \times C)$.

$\Delta A_{300}$, absorbance at $300 \mathrm{~nm}$ using neutral solution as a "blank";

$C$, concentration of lignin, $\mathrm{g} / \mathrm{L}$;

4100, proportionality factor which come from the previous literature [7].

\section{Results and Discussion}

\section{Evaluating dissolving capacity of [Bmim]Cl}

a

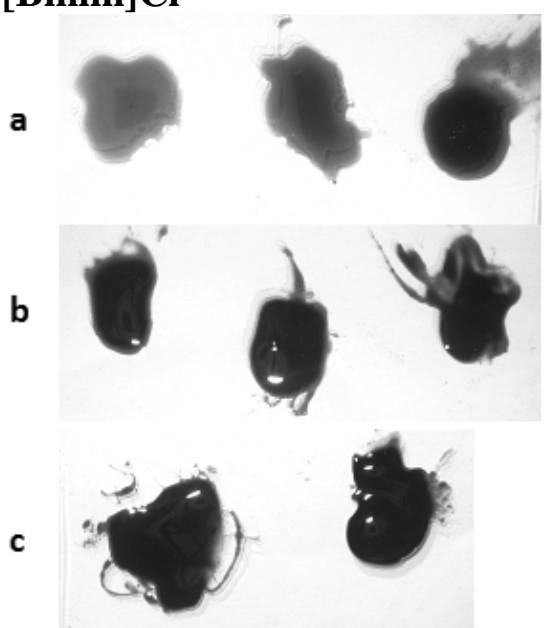

Fig 1 Mixture of alkali lignin and $[\mathrm{Bmim}] \mathrm{Cl}$ with various proportion, a. $0.1,0.15$ and $0.2 \mathrm{~g} / \mathrm{g}$; b. $0.3,0.35$ and $0.4 \mathrm{~g} / \mathrm{g} ;$ c. 0.45 and $0.5 \mathrm{~g} / \mathrm{g}$

Alkali lignin was the degradation product of natural lignin in wood or straw, which was obtained by alkali treatment and acidification [9]. Generally, the product was residue of alkaline pulping. Because it can only be dissolved in alkali liquor, it is difficult to be utilized.

$[\mathrm{Bmim}] \mathrm{Cl}$ is a kind of ionic liquid, which can dissolve the lignocellulosic materials. Since straw can be dissolved by [Bmim] $\mathrm{Cl}$, the degradation product, alkali lignin come from straw should be dissolved too. To verify the speculation, we added alkali lignin in [Bmim]Cl inch by inch (see Fig 1). It was found that with the increase of the content of alkali lignin, the colour of solution turned black brown from sandy beige, and the viscosity increased accordingly. The viscosity did not influence the dissolution of alkali lignin in [Bmim] $\mathrm{Cl}$. In a word, $[\mathrm{Bmim}] \mathrm{Cl}$ showed excellent dissolving capacity. It could even dissolve alkali lignin when $0.5 \mathrm{~g}$ alkali lignin was added in $1 \mathrm{~g}[\mathrm{Bmim}] \mathrm{Cl}$. The excellent dissolving capacity made it possible to modify alkali lignin in $[\mathrm{Bmim}] \mathrm{Cl}$ 


\section{Effect of time on phenolation reaction}

Firstly, the reaction time was investigated. Ten gram $[\mathrm{Bmim}] \mathrm{Cl}, 1 \mathrm{~g}$ alkali lignin, $0.25 \mathrm{~g}$ sulphuric acid and $0.5 \mathrm{~g}$ phenol were mixed and heated at $80^{\circ} \mathrm{C}$. The effect of phenolation for zero hour, $2 \mathrm{~h}$ and $6 \mathrm{~h}$ was measured. The result was shown in Fig 2a. It was found that the reaction of phenol and alkali lignin induced the increase of phenolic hydroxyl group content. With the passage of time, the phenolic hydroxyl group content gradually increased. Especially, the phenolic hydroxyl group content increased drastically in initiatory $2 \mathrm{~h}$ and gently in the later 4 hours. The result indicated that Extension of time is better for the reaction. However, it is not uneconomical to take too long time. Hence, we use 4 hours in follow exprement.
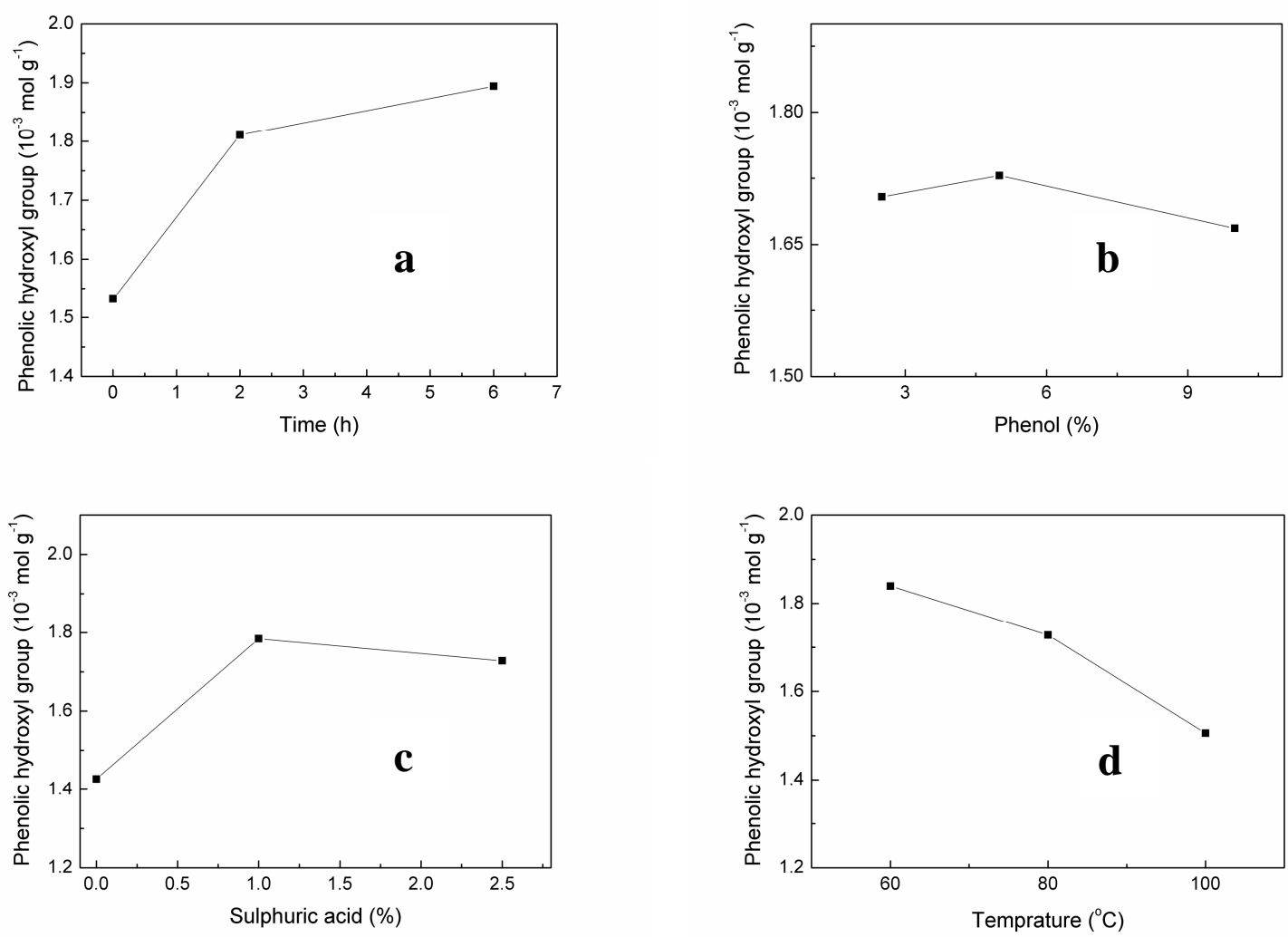

Fig 2 Influence of time (a), phenol amount (b), sulphuric acid amount(c) and temperature (d) on phenolation reaction

\section{Effect of time on phenolation reaction}

The influence of phenol amount on phenolation reaction was investigated too. Ten gram [Bmim]Cl, $1 \mathrm{~g}$ alkali lignin, $0.25 \mathrm{~g}$ sulphuric acid and a certain amount of phenol were mixed and heated at $80{ }^{\circ} \mathrm{C}$

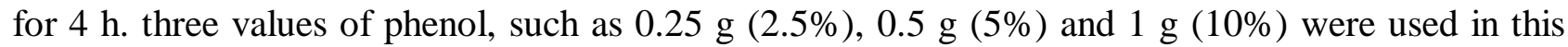
experiment. The result was shown in Fig 2b. It was found that when the phenol amount was $5 \%$ of $[\mathrm{Bmim}] \mathrm{Cl}$, the phenolic hydroxyl group content was highest. However, on the whole, phenol amount does not much affect the reaction.

\section{Effect of sulphuric acid amount on phenolation reaction}

Generally, phenolation is performed at acidic environment. In our research, we investigated the effect of sulphuric acid amount on phenolation. Ten gram [Bmim] Cl, $1 \mathrm{~g}$ alkali lignin, $0.5 \mathrm{~g}$ phenal and some sulphuric acid was mixed and heated at $80{ }^{\circ} \mathrm{C}$ for $4 \mathrm{~h}$. The result was shown in Fig 3c. It was found that the amount of sulphuric acid is an important factor. When the amount was below $1 \mathrm{wt} \%$, the the phenolic hydroxyl group content increased with sulphuric acid amount. When the sulphuric acid amount is higher than $1 \mathrm{wt} \%$, the change of the amount did not affect the phenolation reaction. It was suggested that, $1 \mathrm{wt} \%$ is the optimum value of sulphuric acid amount. 


\section{Effect of temperature on phenolation reaction}

Beside the time and the amount of reactants, temperature is also an important factor. Hence, we investigated the effect of temperature on phenolation reaction. Ten gram $[\mathrm{Bmim}] \mathrm{Cl}, 1 \mathrm{~g}$ alkali lignin, $0.5 \mathrm{~g}$ phenol and $0.25 \mathrm{~g}$ sulphuric acid were mixed and heated at three temperature $\left(60,80\right.$ and $\left.100^{\circ} \mathrm{C}\right)$. The result was shown in Fig $2 \mathrm{~d}$. It was obviously that when the temperature was $60{ }^{\circ} \mathrm{C}$, the highest phenolic hydroxyl group content was obtained. If the temperature increased, the phenolic hydroxyl group content would reduce. We didn't perform the experiment at the temperature below $60{ }^{\circ} \mathrm{C}$ because low temperature lead to high viscosity of ionic liquid.

\section{Conclusion}

The present investigation verified dissolving capacity of $[\mathrm{Bmim}] \mathrm{Cl}$ and researched the effect of some influencing factors, such as time, temperature and the amount of reactants, on the phenolation reaction in $[\mathrm{Bmim}] \mathrm{Cl}$. The results suggested that alkali lignin can be dissolved in $[\mathrm{Bmim}] \mathrm{Cl}$, and the phenolation of alkali lignin in $[\mathrm{Bmim}] \mathrm{Cl}$ is feasible.

\section{Acknowledgments}

This work was supported by the University-Institute Cooperation Funds from UCAS (No. Y552017Y00) and the Start-up Research Funds for Young Teachers from UCAS (No. Y55103GY00).

\section{References}

[1] J. Podschun, A. Stücker, B. Saake, R. Lehnen, Structure-Function Relationships in the Phenolation of Lignins from Different Sources. ACS Sustain. Chem. eng. 3(2015):2526-2532

[2] J. Podschun, B. Saake, R. Lehnen, Reactivity enhancement of organosolv lignin by phenolation for improved bio-based thermosets. Eur. Polym. J. 67(2015):1-11

[3] M. Funaoka, M. Matsubara, N. Seki, S. Fukatsu, Conversion of native lignin to a highly phenolic functional polymer and its separation from lignocellulosics. Biotechnol. Bioeng. 46(1995):545-552

[4] M. V. Alonso, M. Oliet, F. Rodriguez, J. Garcia, M. Gilarranz, J. Rodriguez, Modification of ammonium lignosulfonate by phenolation for use in phenolic resins. Bioresource Technol. 96(2005):1013-1018

[5] B. Xiao, X. Sun, R. Sun, Chemical, structural, and thermal characterizations of alkali-soluble lignins and hemicelluloses, and cellulose from maize stems, rye straw, and rice straw. Polym. Degrad. Stabil. 74(2001):307-319

[6] P. Mäki-Arvela, I. Anugwom, P. Virtanen, R. Sjöholm, J-P. Mikkola,Dissolution of lignocellulosic materials and its constituents using ionic liquids - a review. Ind. Crop Prod. 32(2010):175-201

[7] O. Goldschmid, Determination of phenolic hydroxyl content of lignin preparations by ultraviolet spectrophotometry. Anal. Chem. 26(1954):1421-1423

[8] A. S. Wexler, Characterization of lignosulfonates by ultraviolet spectrometry. Direct and difference spectrograms. Anal. Chem. 36(1964):213-221

[9] M. Dolk, F. Pla, J. F. Yan, J. L. McCarthy, Lignin. 22. Macromolecular characteristics of alkali lignin from western hemlock wood. Macromolecules 19(1986):1464-1470 